\title{
Active Methylene-based Multicomponent Reactions under Microwave Heating
}

\author{
Bo Jiang and Shu-Jiang Tu*
}

\begin{abstract}
The use of emerging multicomponent reactions (MCRs) in conjunction with microwave (MW)-assisted chemistry techniques is dramatically reducing chemical waste and reaction times in several organic syntheses and chemical transformations. MW-assisted active methylene-based multicomponent reactions serve as a rapid and efficient tool for the synthesis of versatile heterocycles, particularly those containing structural diversity and complexity via a one-pot operation. This minireview covers our recent advances on multicomponent reactions involving active methylene compounds for the construction of bioactive molecule skeletons. In many cases, MWassisted MCRs offer considerable improvements in selectivity, chemical yield and purity and constitutes a very simple and extremely rapid method to access a diverse range of heterocyclic motifs.
\end{abstract}

Keywords: Active methylene compounds · Green synthesis · Heterocycles · Microwave heating · Multicomponent reaction

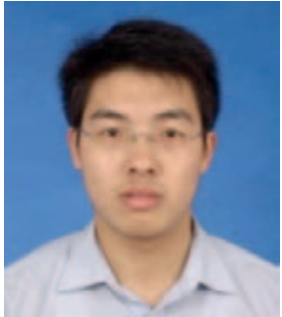

Bo Jiang was born in 1981 in Jiangsu, China. He received his Ph.D. in 2010 from the Suzhou University under the supervision of professors Shu-Jiang Tu and Guigen Li. His research interests include multicomponent reaction, domino reaction and the innovation of synthetic methods.

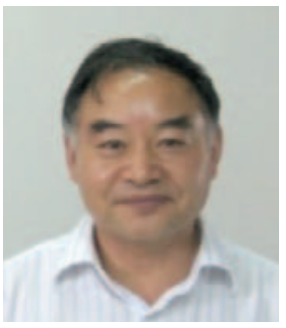

Shu-Jiang $\boldsymbol{T} \boldsymbol{u}$ was born in 1957 in Jiangsu, China, and received his B.Sc. in 1983. He was appointed as assistant professor at the Xuzhou Normal University in 1999, and was promoted to full Professor in 2003. His current interests are the development of new synthetic methods, green chemistry, and microwave multicomponent syntheses.

${ }^{\star}$ Correspondence: Prof. S.-J. Tu, Dr. B. Jiang Xuzhou Normal University, P. R. China

College of Chemistry and Chemical Engineering, and Jiangsu Key Laboratory of Green Synthetic Chemistry for Functional Materials

Tel.: +86516 83500065

Fax: +8651683500065

E-mail: laotu@xznu.edu.cn, jiangchem@xznu.edu.cn

\section{Introduction}

The creation of molecular complexity and diversity from simple substrates, ${ }^{[1]}$ while combining economic aspects ${ }^{[2,3]}$ with environmental ones, ${ }^{[4]}$ constitutes a great challenge in modern organic chemistry, from both academic and industrial points of view. ${ }^{[5]}$ Multicomponent reactions ${ }^{[6]}$ (MCRs) involving domino processes, ${ }^{[7]}$ with at least three different substrates reacting in a well-defined manner to form a single compound, have provided a most powerful platform to access diversity as well as complexity in a limited number of reaction steps. ${ }^{[8]}$ Besides generating structural complexity in a single step, MCRs offer the advantage of simplicity and synthetic efficiency over conventional chemical reactions. The mechanisms of multicomponent reactions are often complex assemblies of two-component reactions. In the ideal case, all sub-reactions involved are reversible equilibrium reactions, while only the last product forming step is irreversible. Thereby, multicomponent reactions can yield the desired product with higher yield and purity when compared with a synthesis procedure that uses a sequence of two-component reactions towards the same product. Since the pioneering work by Strecker in 1850 illustrating the first reported MCR, [9] this now well-known concept ${ }^{[10]}$ has been extensively used in both liquid-phase and solid-phase ${ }^{[11]}$ chemistry for the rapid assembly of complex heterocyclic structures of importance for pharmaceutical development.[12] Although isocyanidebased MCRs, ${ }^{[6,13]}$ introduced in 1921 by Passerini, ${ }^{[14]}$ generally predominate nowadays for the construction of widely diverse heterocycles, ${ }^{[15]}$ one of the most important substrate classes involved in a MCR is that of active methylene compounds including cyano compounds, (cyclic-)1,3-dicarbonyls and monocarbonyl derivatives, with remarkable application in heterocycle synthesis and related chemistry. ${ }^{[16]}$

With methylene linking one or two strongly electron-withdrawing groups, active methylene compounds constitute important synthetic intermediates, incorporating multiple functionalities that can be involved either as nucleophilic or electrophilic species in a large variety of synthetic transformations. [17] Their versatility and effectiveness as potential multicomponent substrates have been utilized in various reactions for more than a century, allowing development of new useful methodologies valuable for the selective construction of highly functionalized small organic molecules of high synthetic and biological value. The aim of this minireview is to present an overview of the high synthetic potential of MCRs involving the specific reactivity of easily accessible active methylene compounds and to highlight our more recent utilization for the development of new useful methodologies valuable for the selective construction of highly functionalized small organic molecules of high synthetic and biological value.

\section{Multicomponent Reactions Involving Cyano Compounds}

It is well-known that cyano compounds can serve as an exceptionally versatile building block; they have been extensively 

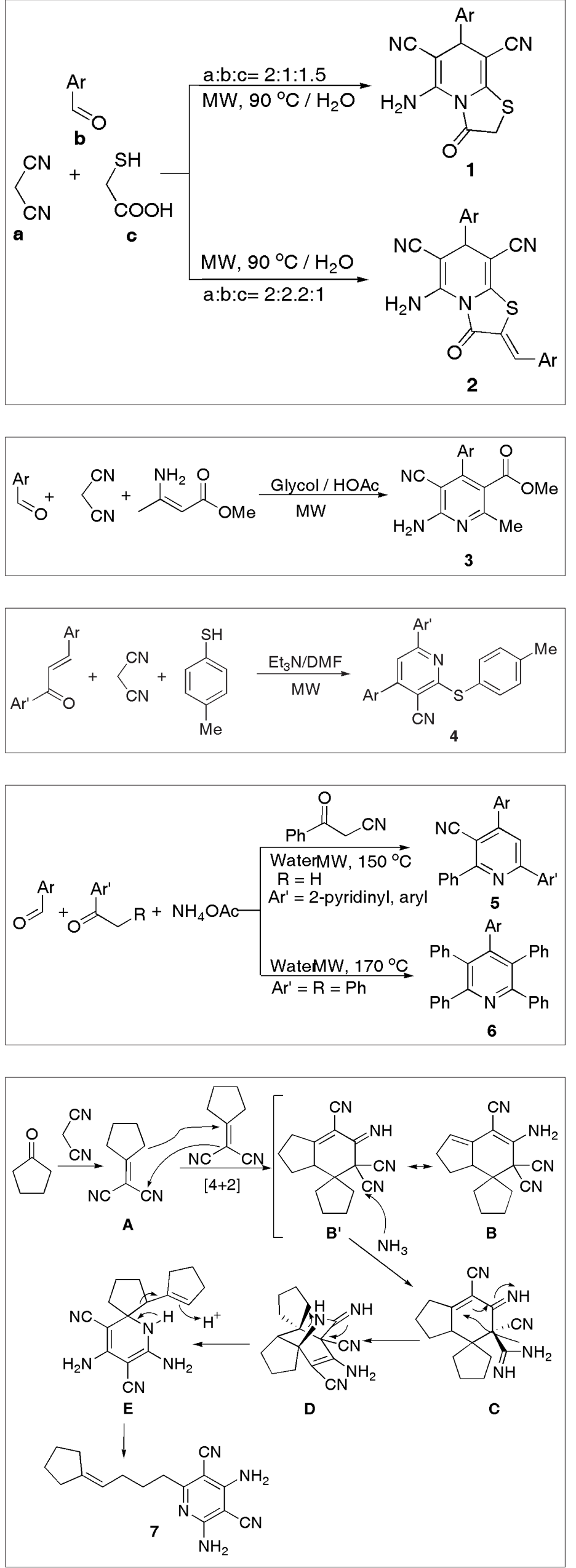

Scheme 1.

Multicomponent

synthesis of

thiazolo[3,2-a]

pyridines.

Scheme 2.

Multicomponent synthesis of pyridines.

Scheme 3. Threecomponent synthesis of pyridines.

Scheme 4. Multicomponent synthesis of polysubstituted pyridines.

Scheme 5. Multicomponent domino synthesis of pyridines. used as reactants or intermediates in organic synthesis. These compounds exhibit unique reactivity due to the fact that the strongly electron-withdrawing cyano group can activate the methylene $\mathrm{CH}_{2}$; the cyano group can be a good leaving group for substitution reactions with its polar multiple bonds being suitable for nucleophilic additions. Both methylene group and cyano group can participate in condensation reactions to give a variety of addition products and heterocyclic compounds. ${ }^{[18]}$ This exceptional behavior furthermore makes cyano compounds important candidates for the design of new practical multicomponent syntheses serving medicinal, industrial and agricultural research. ${ }^{[19]}$

The MCR of malononitrile, aromatic aldehydes and 2-mercaptoacetic acid was preformed to produce two different products by controlling the molar ratios of the starting materials. The thiazolo[3,2-a] pyridine derivatives $\mathbf{1}$ and $\mathbf{2}$ were chemoselectively synthesized in water (Scheme 1). These products have been screened for their antioxidant activity and cytotoxicity in carcinoma HCT-116 cells and mice lymphocytes. Nearly all of the tested compounds possessed potent antioxidant activity. ${ }^{[20]}$

Subsequently, instead of 2-mercaptoacetic acid, methyl 3-aminobut-2-enoate was employed together with aromatic aldehydes and malononitrile, and eleven examples of methyl 4-substituted-6amino-5-cyano-2-methylpyridine-3carboxylates $\mathbf{3}$ in $82-89 \%$ chemical yields were obtained within 6-10 $\mathrm{min}$ (Scheme 2). ${ }^{[21]}$ The three-component reaction of $\alpha, \beta$-unsaturated ketones with malononitrile and 4-methylbenzenethiol in DMF was achieved using $\mathrm{Et}_{3} \mathrm{~N}$ as a base catalyst under microwave heating (Scheme 3 ). Fourteen examples of 2-thiopyridines 4 with excellent yields of $89-95 \%$ were directly synthesized, and this provides an efficient synthetic strategy to construct polysubstituted pyridine skeleton with the advantage of short time, excellent yield, and convenient operation. ${ }^{[22]}$

The similar pyridines $\mathbf{5}$ in water at high temperatures were generated through an efficient reagent-controlled multicomponent reaction under microwave heating. The reaction was completed by reacting aldehydes with 3-aryl-3oxopropanenitrile, 2-acetylpyridine, and ammonium acetate. Furthermore, aromatic aldehydes reacted with 1,2-diphenylethanone, resulting in structurally complex penta-arylpyridines 6 (Scheme 4). ${ }^{[23]}$

Recently, $\mathrm{Tu}$ and Li's group described the multicomponent reaction of malononitrile and cyclopentanone in presence of an excess amount of ammonium acetate. The reaction gave best 


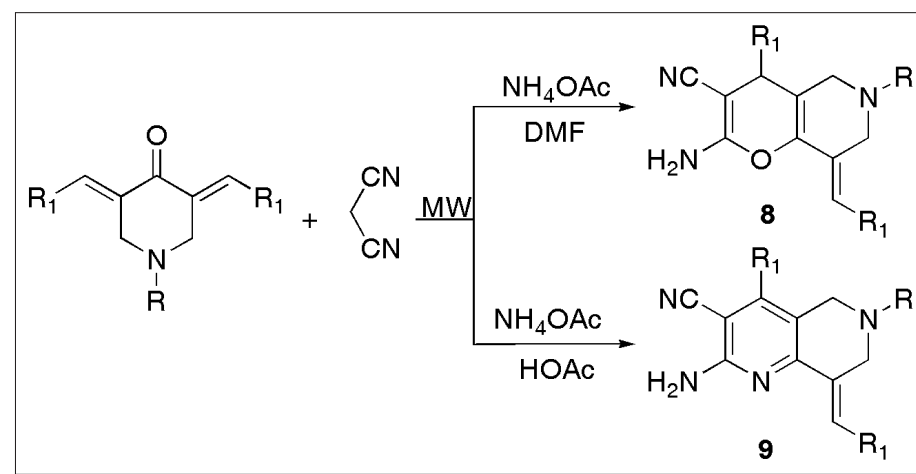

Scheme 6.

Chemoselective

synthesis of

pyrano[3,2-c]

pyridines or

1,6-naphthyridines.

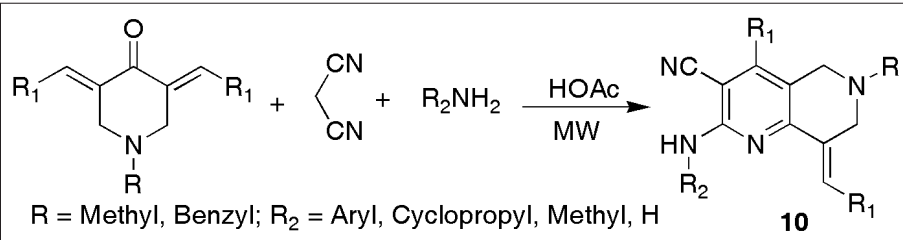

Scheme 7.

Multicomponent

synthesis of

1,6-naphthyridines.<smiles></smiles>

Scheme 8. The multicomponent synthesis fused pyranophenazines.

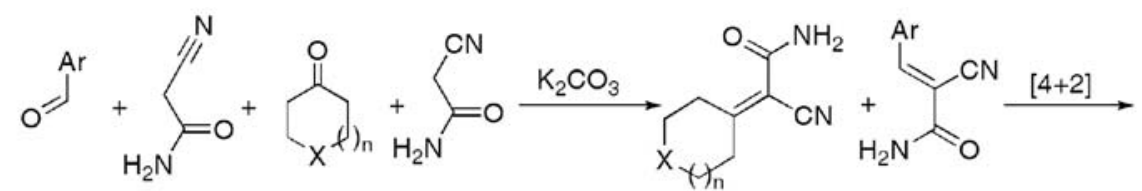

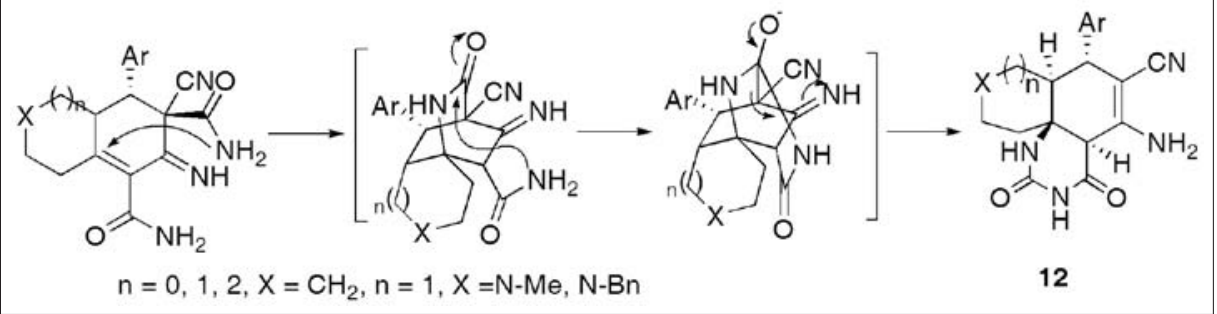

Scheme 9. Multicomponent domino synthesis of quinazolines.

results under solvent-free conditions and microwave irradiation. Six examples of highly functionalized pyridine derivatives 7 in 41-81\% yields were synthesized, and their structures were fully characterized by NMR, HRMS and IR spectral analysis (Scheme 5). The new domino reaction enables successful assembly of five new $\sigma$ bonds including two $\mathrm{C}-\mathrm{N}$ bonds in a onepot operation. A new mechanism has been proposed, which involves a novel reaction and sequence consisting of deprotonation - imine formation - anionic carbonyl addition. ${ }^{[24]}$

Various naphthyridine derivatives showed a wide range of biological activities, such as antitumor, anti-inflammatory, and antifungal properties. ${ }^{[25]}$ Compounds incorporating this motif are useful in the treatment of hypertension, myocardial infarction, hyperlipidemia, cardiac arrhythmia, and rheumatoid arthritis.[26] Therefore, the synthesis of these compounds is of great significance. Tu's group reported chemoselective synthesis of a series of pyrano[3,2-c] pyridines $\mathbf{8}$ and 1,6-naphthyridines $\mathbf{9}$ under microwave heating (Scheme 6). The reactions of $\alpha, \beta$-unsaturated ketones reacted with malononitrile and ammonium acetate were controlled by the nature of the solvent. ${ }^{[27]}$ HOAc as solvent resulted in 15 examples of 1,6-naphthyridines in $89-94 \%$ yields whereas DMF led to 12 examples of pyrano[3,2-c]pyridines with $89-95 \%$ yields. Synthesis using the same method resulted in polysubstituted 1,6-naphthyridines $\mathbf{1 0}$ as reported by the same group (Scheme 7). ${ }^{[28]}$

A one-pot two-step tandem synthesis of highly functionalized benzo[a] pyrano[2,3-c]phenazine derivatives $\mathbf{1 1}$ via microwave-assisted multicomponent reactions of 2-hydroxynaphthalene1,4-dione, diamines, aldehydes, and malononitrile was presented by Tu's group (Scheme 8). The 2-hydroxynaphthalene1,4-dione first reacted with diamines to yield benzo[a]phenazin-5-ol followed with aldehydes, and malononitrile, providing 26 examples of the desired products with total yields of $81-92 \%$. The procedures are facile, avoiding time-consuming and costly syntheses, tedious workup, and purifications of precursors, as well as protection/deprotection of functional groups. ${ }^{[29]}$

$\mathrm{Tu}$ and $\mathrm{Li}$ et al. recently developed a new four-component domino reaction between simple aldehydes, cycloketones and cyanoamides to obtain a diverse set of quinazoline derivatives 12 in 74-90\% yields, with remarkable chemo-, regio-, and stereoselectivity (Scheme 9). [30] The reaction, which is easily performed, is done by simply mixing four common reactants and $\mathrm{K}_{2} \mathrm{CO}_{3}$ in ethylene glycol under microwave irradiation; the reaction can be achieved within 10-24 min, leaving water as the only byproduct, which makes the work-up convenient. This reaction demonstrates the efficiency of domino MCR with four stereogenic centers with one quaternary carbon-amino function being controlled very well. Later on, the same group found that when aromatic aldehydes were replaced by their aliphatic counterparts, the quinazoline derivatives were not generated. Interestingly, the reaction resulted in the formation of multi-functionalized tricyclo[6.2.2.0 $\left.0^{1,6}\right]$ dodecanes 13. These novel scaffolds belong to another very important class of compounds for organic synthesis and drug design in pharmaceutical sciences (Scheme 10). [31]

A sequential one-pot, tandem reaction 


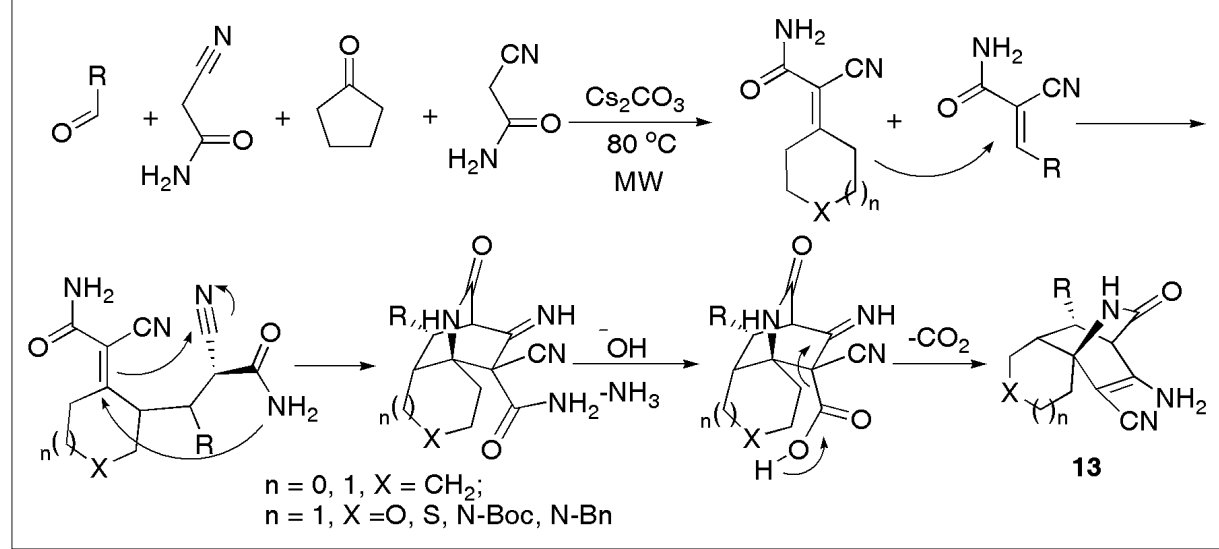

Scheme 10. Multicomponent domino synthesis of tricyclo[6.2.2.01,6]dodecanes.

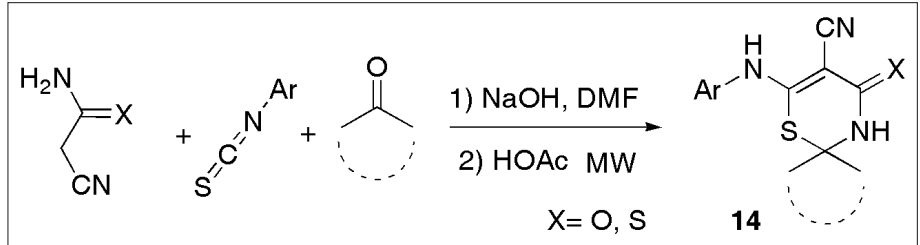

Scheme 11.

Tandem synthesis

of spiro-substituted

1,3-thiazines. for efficient synthesis of a spiro-substituted 1,3-thiazine library $\mathbf{1 4}$ has been developed by Tu's group (Scheme 11). The syntheses were achieved by reacting cyanoacetamide with isothiocyanate derivatives to give rise to 2-cyano-3-mercaptoacrylamides, which are trapped in situ by various cycloketones through cyclization, providing multifunctionalized spirosubstituted 1,3-thiazine analogues with good to excellent total yields $(81-91 \%){ }^{[32]}$

\section{Multicomponent Reactions Involving 1,3-Dicarbonyls}

Meldrum's acid, a type of 1,3-dicarbonyl, shows several unique features such as high acidity $\left(\mathrm{p} K_{\mathrm{a}} 4.83\right)$, steric rigidity, and a notable tendency to regenerate acetone as an easily removable sideproduct. ${ }^{[33]}$ Furthermore, its unique ringopening reactions make it a tremendously attractive and useful building block. MCRs involving Meldrum's acid generally retain the unique ring-captured malonic acid moiety, which can be released by loss of acetone, when reacting with nucleophiles. This reaction is frequently accompanied with partial decarboxylation. In this way various diversity elements can be built into the diverse MCR products. Therefore, the synthetic applications of Meldrum's acid in the design of new MCRs have attracted considerable attention. Recently, Tu's group developed several new Meldrum's acidbased MCRs. A new class of $\alpha$-lapachone derivatives $\mathbf{1 5}$ was prepared from the reaction of aromatic aldehydes, Meldrum's acid and 2-hydroxynaphthalene-1,4-dione under microwave irradiation (Scheme 12).
The twelve examples of $\alpha$-lapachones with 83-93\% yields in HOAc were achieved in one-pot manner within 3-6 min. This procedure is advantageous both economically and environmentally. [34]

Later on, nine examples of new pyrazolo[4,3-f]quinolin-7-ones $\mathbf{1 6}$ were synthesized by multi-component reactions of equimolar amount of aromatic aldehydes with 2,2-dimethyl-1,3-dioxane-4,6-dione and $1 \mathrm{H}$-indazol-5-amine in ethylene glycol without catalyst under microwave irradiation (Scheme 13). ${ }^{[35]}$ A similar method to produce indeno[2,1-f]quinolin$3(2 \mathrm{H})$-one derivatives has been described by the same group. ${ }^{[36]}$

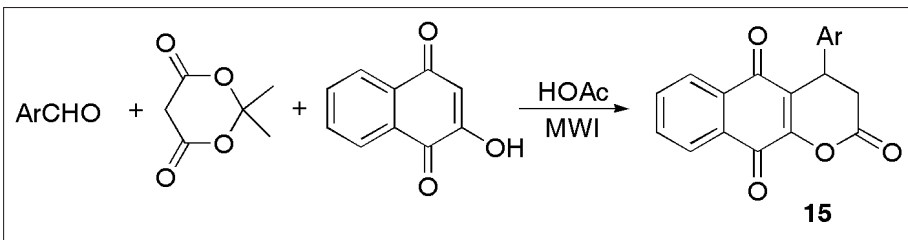

Scheme 12. Threecomponent synthesis of spiro-substituted 1,3-thiazines.

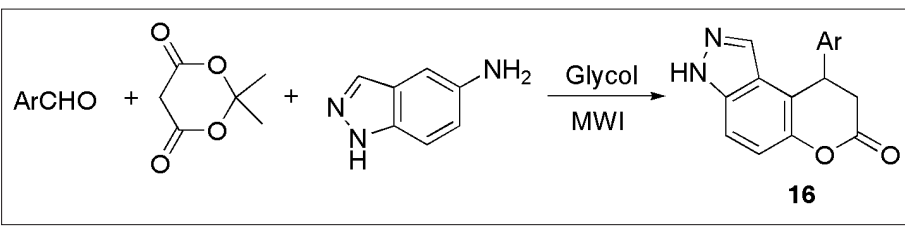

Scheme 13. Threecomponent synthesis of quinolinones.

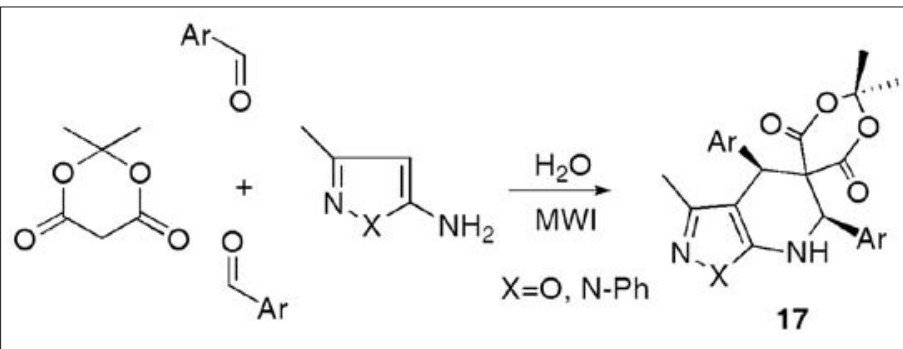

Scheme 14. Fourcomponent synthesis of spiro-substituted Meldrum's acid. 


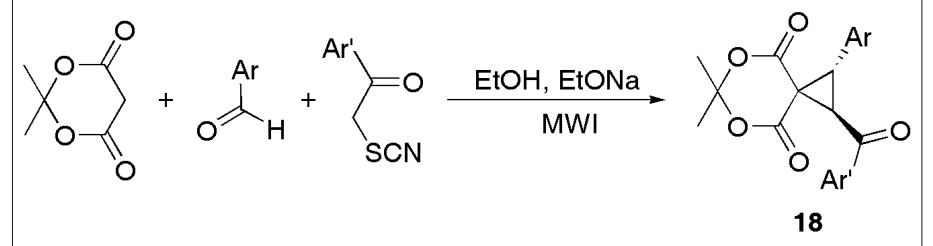

Scheme 15. Three-component synthesis of trans-cyclopropanes.

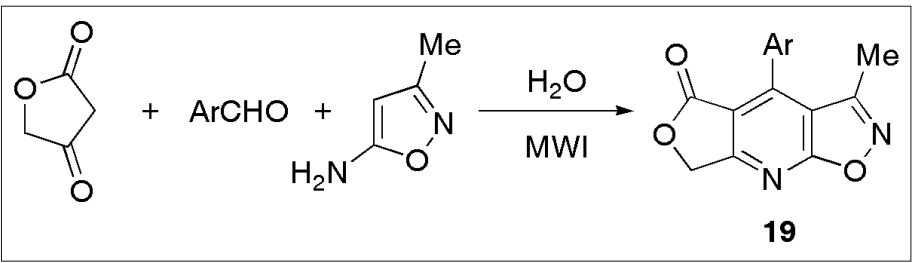

Scheme 16. Green synthesis of fused tetronic acids.

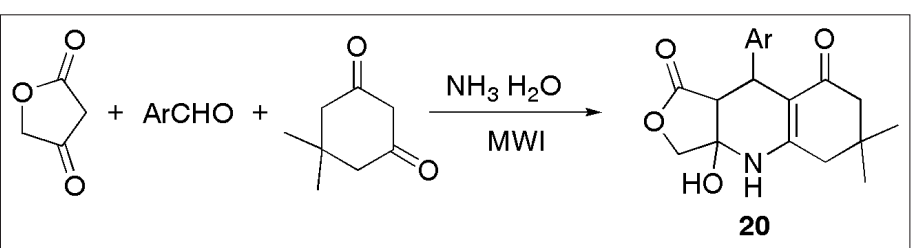

Scheme 17. Green synthesis of azapodophyllotoxin derivatives.

three-component reaction of aldehyde, 3-methylisoxazol-5-amine, and tetronic acid (Scheme 16). The reaction provided eight examples of tetronic acids in 84$91 \%$ yields within a short period (3-7 min). Other active methylene compounds, such as 1,3-indanedione, cyclohexane1,3-dione, dimedone and Meldrum's acid were suitable for this reaction, providing a series of polycyclic-fused isoxazolo[5,4-b] pyridines. ${ }^{[46]}$

In addition, tetronic acid was employed to react with dimedone and aldehyde in the presence of aqueous ammonia under microwave heating, resulting in four examples of azapodophyllotoxin derivatives 20 in 81-88\% yields (Scheme 17). ${ }^{[47]}$ Next, Tu and Li described new regioand chemoselective $[4+2+1]$ domino cyclization for the synthesis of spiro- substituted benzo[b]furo[3,4-e][1,4]diazepine derivatives $\mathbf{2 1}$ and $\mathbf{2 2}$ consisting of the formation of two spiro rings and five $\sigma$ bonds (Scheme 18). The reaction is a multicomponent domino green process and can be readily performed by reacting inexpensive starting materials of benzene-1,2-diamines, tetronic acid and 2,2-dihydroxy-2H-indene-1,3-dione in aqueous solution under microwave irradiation. The present synthesis shows attractive characteristics, such as the use of water as reaction media, convenient one-pot operation, short reaction periods of 10-18 min. ${ }^{[48]}$ When 2,2-dihydroxy-2H-indene1,3-dione were replaced by aromatic aldehydes, the reaction resulted in the formation of multi-functionalized benzo $[f]$ azulen-1-ones $\mathbf{2 3}$ with good to excellent yields (Scheme 19). The directing effects of substituents on benzene-1,2-diamine ring have been proven to control regioselectivity efficiently. ${ }^{[49]}$ To expand the substrate scope of this reaction, 2-formylbenzoic acids were employed to react with benzene-1,2-diamines and tetronic acid. These reactions gave pentacyclic isoindole-fused furo[1,4]diazepines $\mathbf{2 4}$ in $80-88 \%$ yields (Scheme 20). ${ }^{[49,50]}$

The same group established a new multicomponent domino reaction for rapid and regioselective synthesis of highly functionalized benzo[h]pyrazolo[3,4-b] quinolines 25 . The reaction can be conducted by using aldehydes, 2-hydroxy-1,4naphthoquinone and pyrazol- or isoxazoloamines as substrates under microwave irradiation within short periods of 10-26 min. Good to excellent chemical yields (61-91\%) and complete regioselectivity have been achieved for 22 examples. The resulting benzoquinolines have been readily converted into quinoxalinefused benzo[h]isoxazolo[5,4-b]quinoline analogues 26 by treating with benzene1,2-diamine under microwave irradiation (Scheme 21). ${ }^{[51]}$

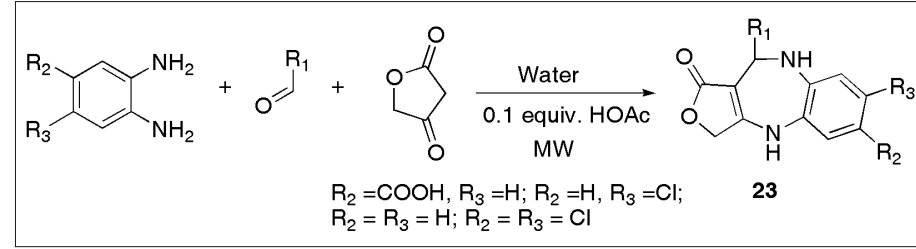

Scheme 19. Regioselective synthesis of benzo[f]azulen-1-ones.

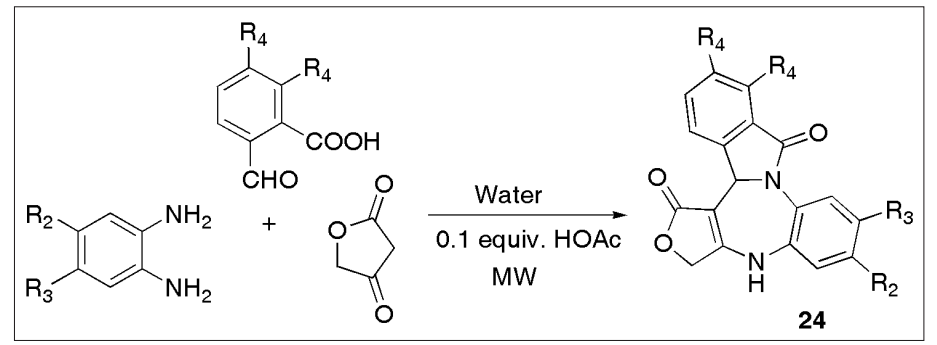

Scheme 20. Synthesis of pentacyclic isoindole-fused furo[1,4]diazepines.

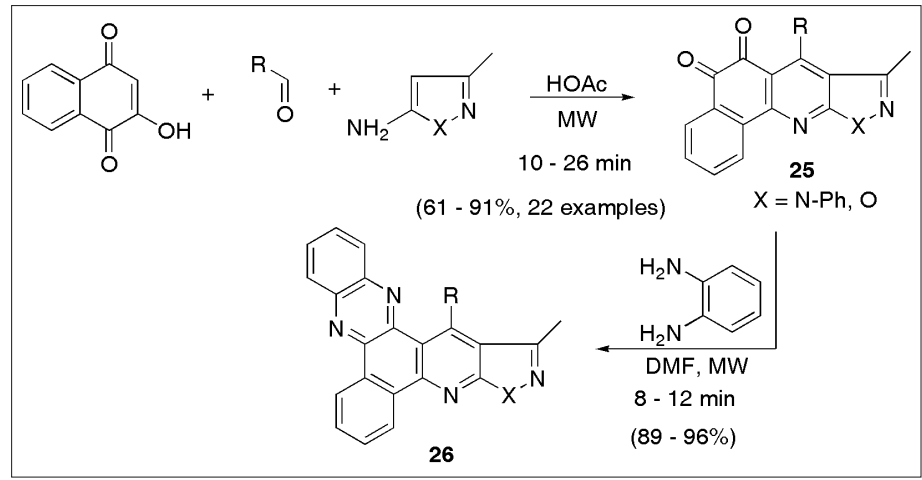

Scheme 21. Synthesis of quinoxaline-fused benzo[h]isoxazolo[5,4-b] quinolines. 


\section{Multicomponent Reaction Involving Other Active Methylene Derivatives}

Mannich reactions are among the most important carbon-carbon bond forming reactions in organic synthesis. They provide $\beta$-amino carbonyl compounds, which are important synthetic intermediates for various pharmaceuticals and natural products.[52] Tu's group presented a new mild base-catalyzed Mannich reaction of aromatic aldehydes with 1,2-diphenylethanone and heteroarylamines including pyridin-2-amine and pyrimidin-2-amine (Scheme 22). In this reaction, 20 examples of new $\beta$-aminoketones $\mathbf{2 7}$ were stereoselectively synthesized in water by controlling the steric hindrance of the substrates under microwave heating. This method has the advantages of a short reaction periods (10-28 min), operational simplicity, and minimal environmental impact. [53]

Similar substrates were employed in one-pot operation in the presence of potassium carbonate, and the reaction underwent another route to a variety of substituted benzo[4,5]imidazo[1,2-a]pyrimidine derivatives $\mathbf{2 8}$ (Scheme 23). ${ }^{[54]}$ A similar method to produce 5,6,7-triarylpyrido[2,3-d]pyrimidin-4-ones $\mathbf{2 9}$ was reported by the same group. Moreover, these novel compounds were tested for in vitro cytotoxicity to carcinoma SW1116 and SGC7901 cells. Most of the tested compounds showed significant cytotoxicity to SW1116 cells (Scheme 24). ${ }^{[55]}$ To further expand the application of the multicomponent reaction, aldehydes, aminopyrazole and cycloketones were employed in one-pot reactions (Scheme 25). As a result, a series of new functionalized macrocyclane-fused pyrazolo[3,4- $b]$ pyridine derivatives $\mathbf{3 0}$ and 31with an aryl group at the 2-position of the pyridine nucleus were synthesized under microwave heating in HOAc using 1.0 equiv. of TFA as a promoter. This method is very efficient due to short reaction times (11-15 min) and easy workup and provides an efficient and promising synthetic strategy for the construction of the macrocyclane-fused pyrazolo[3,4-b] pyridine skeleton. ${ }^{[56]}$

$\underset{\mathrm{O}}{\mathrm{Ar}}+\overbrace{\mathrm{X}=\mathrm{CH}, \mathrm{N}}^{\mathrm{X}} \underset{\substack{130^{\circ} \mathrm{C} \mathrm{MW} \\ \text { Sealed }}}{\mathrm{N}_{\mathrm{Ph}}}$
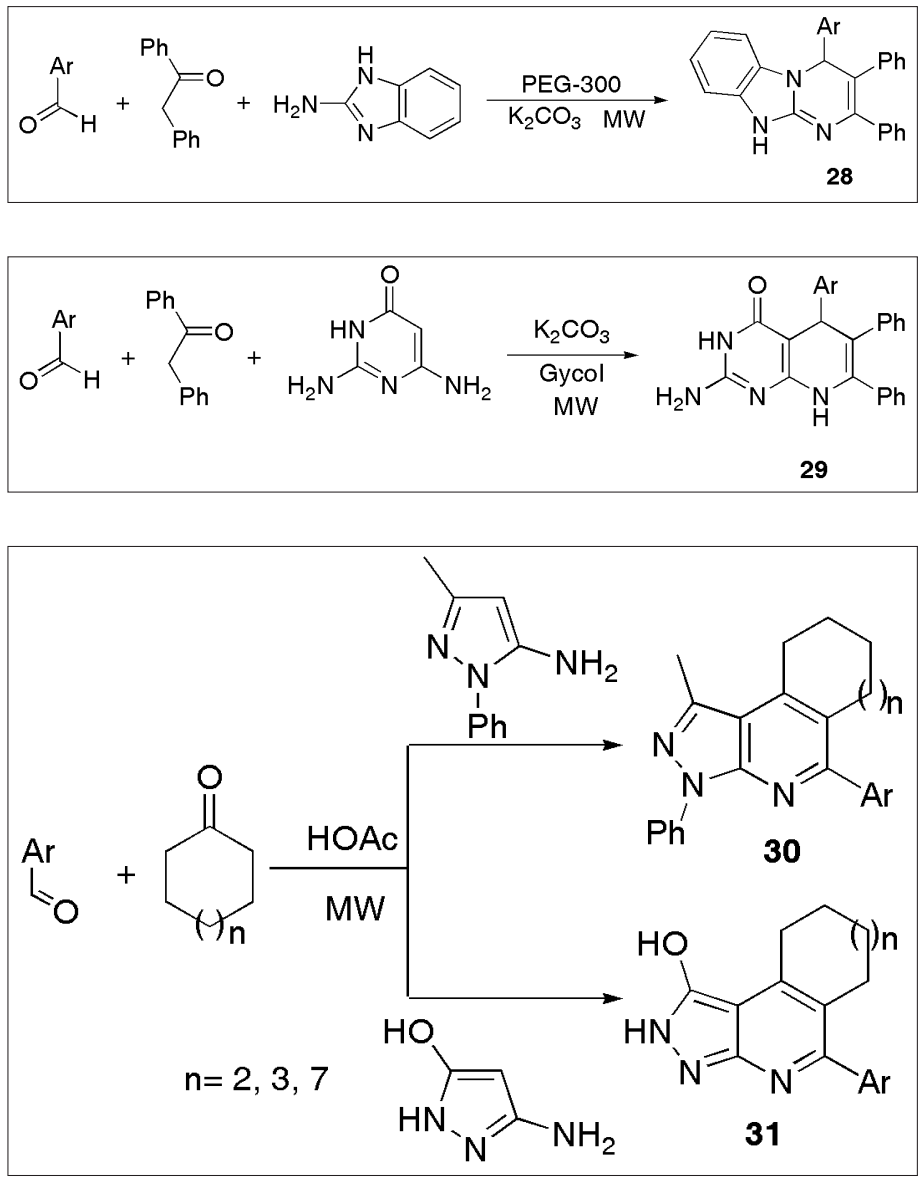

\section{Conclusion}

The critical selection of the diverse MCRs developed over more than one century clearly shows that simple active methylene derivatives still constitute versatile substrates in organic chemistry which have offered increasingly important opportunities for synthesis of both chemically and biomedically useful compounds because of their environmentally friendly characteristics of atom-economy and green chemistry. These reactions enable multi-step processes to be achieved in a single step of operation to produce a diverse variety of products that include useful heterocycles with structural complexity. Future development of new synthetic transformations involving the high reactivity of methylene compounds towards many other substrates will enlarge the scope of this field, allowing the facile and selective construction of highly functionalized small organic molecules of high synthetic and biological value.

\section{Acknowledgment}

We are grateful for financial support from the NSFC (Nos. 21072163, 21002083, and 21102124), PADA of Jiangsu Higher Education Institutions, the Natural Science Foundation (11KJB150016) of Jiangsu Education Committee, and Sci. Foundation in Interdisciplinary Major Res. Project of XZNU (No. 09XKXK01).

Received: September 25, 2011

Scheme 23.

Green synthesis

of imidazo[1,2-a] pyrimidines.

Scheme 24. Threecomponent synthesis of pyridopyrimidines.

Scheme 25.

Three-component synthesis of macrocyclane-fused pyrazolopyridine.
[1] S. L. Schreiber, Science 2000, 287, 1964.

[2] Step-economy: a) P. A. Wender, F. C. Bi, G. G. Gamber, F. Gosselin, R. D. Hubbard, M. J. C. Scanio, R. Sun, T. J. Williams, L. Zhang, Pure Appl. Chem. 2002, 74, 25; b) P. A. Wender, J. L. Baryza, S. E. Brenner, M. O. Clarke, G. G. Gamber, J. C. Horan, T. C. Jessop, C. Kan, K. Pattabiraman, T. J. Williams, Pure Appl. Chem. 2003, 75, 143; c) P. A. Wender, J. L. Baryza, S. E. Brenner, M. O. Clarke, M. L. Craske, J. C. Horan, T. Meyer, Curr. Drug Discov. Technol. 2004, 1, 1; d) P. A. Wender, G. G. Gamber, R. D. Hubbard, S. M. Pham, L. Zhang, J. Am. Chem. Soc. 2005, 127, 2836.

[3] Atom-economy: a) B. M. Trost, Science 1991, 254, 1471; b) B. M. Trost, Angew. Chem., Int. Ed. 1995, 34, 258; c) B. M. Trost, Acc. Chem. Res. 2002, 35, 695.

[4] For a special issue in environmental chemistry, see Chem. Rev. 1995, 95, 3

[5] L. Weber, M. Illgen, M. Almstetter, Synlett 1999, 36.

[6] a)For a recent monograph, see: 'Multicomponent Reactions', Eds: J. Zhu, H. Bienayme, WileyVCH, Weinheim, 2005; b) For a special issue in MCRs, see Tetrahedron, 2005, 61, 11299. For some recent reviews of MCRs, see: c) $\mathrm{H}$. Bienayme, C. Hulme, G. Oddon, P. Schmitt, Chem. Eur. J. 2000, 6, 3321; d) A. Domling, I. Ugi, Angew. Chem., Int. Ed. 2000, 39, 3168; e) J. Zhu, Eur. J. Org. Chem. 2003, 1133; f) R. V. Orru, M. de Greef, Synthesis 2003, 1471; g) D. J. Ramon, M. Yus, Angew. Chem., Int. Ed. 2005, 44, 1602; h) C. Simon, T. Constantieux, J. Rodriguez, Eur. J. Org. Chem. 2004, 4957. 
[7] For representative reviews, see: a) L. F. Tietze, Chem. Rev. 1996, 96, 115; b) L. F. Tietze, M. E Lieb, Curr. Op. Chem. Biol. 1998, 2, 363; c) J. Rodriguez, Synlett 1999, 505.

[8] a) B. Groenendaal, E. Ruijter, R. V. A. Orru, Chem. Commun. 2008, 5474; b) N. Ismabery, R. Lavila, Chem.-Eur. J. 2008, 14, 8444; c) J. D. Sunderhaus, S. F. Martin, Chem.-Eur. J. 2008 15, 1300; d) B. Jiang, F. Shi, S.-J. Tu, Curr. Org. Chem. 2010, 14, 357; e) B. Ganem, Acc. Chem. Res. 2009, 42, 463; f) L. F. Tietze, T. Kinzel, C. C. Brazel, Acc. Chem. Res. 2009, 42, 367.

[9] A. Strecker, Liebigs Ann. Chem. 1850, 75, 27.

[10] G. H. Posner, Chem. Rev. 1986, 86, 831.

[11] S. L. Dax, J. J. McNally, M. A. Youngman, Curr. Med. Chem. 1999, 6, 255.

[12] A. Nefzi, J. M. Ostresh, R. A. Houghten, Chem. Rev. 1997, 97, 449.

[13] a) A. Domling, Curr. Op. Chem. Biol. 2000, 4, 318; b) A. Domling, I. Ugi, Angew. Chem., Int. Ed. 2000, 39, 3168; c) A. Domling, Curr. Op. Chem. Biol. 2002, 6, 306.

[14] a) M. Passerini, Gazz. Chim. Ital. 1921, 51, 126 b) M. Passerini, Gazz. Chim. Ital. 1921, 51, 181 .

[15] I. Ugi, A. Domling, B. Werner, J. Heterocyclic. Chem. 2000, 37, 647.

[16] a) C. Simon, T. Constantieux, J. Rodriguez, Eur. J. Org. Chem. 2004, 4957; b) F. Freeman, Chem. Rev. 1969, 69, 591; c) A. J. Fatiadi, Synthesis 1978, 241; d) A. Saikia, Synlett 2004, 2247.

[17] a) S. Benetti, R. Romagnoli, C. De Risi, G. Spalluto, V. Zanirato, Chem. Rev. 1995, 95, 1065; b) P. Langer, Chem. Eur. J. 2001, 7, 3858 c) P. Langer, Synthesis 2002, 441.

[18] a) L. Rodinovskaya, A. Shestopalov, A. Gromova, A. Shestopalov, Synthesis $\mathbf{2 0 0 6}$ 2357; b) V. Nair, A. Deepthi, P. B. Beneesh, S. Eringathodi, Synthesis 2006, 14436; c) S Balalaie, M. Bararjanian, A. M. Amani, B. Movassagh, Synlett 2006, 263; d) F. Fringuelli, O. Piermatti, F. Pizzo, Synthesis 2003, 2331; e) M. Adib, B. Mohammadi, S. Ansari, H. R Bijanzadeh, L.-G. Zhu, Synthesis 2010, 1526; f) M. N. Elinson, A. I. Ilovaisky, V. M. Merkulova, P. A. Belyakov, A. O. Chizhov, G. I. Nikishin, Tetrahedron 2010, 66, 4043.

[19] a) S. Marchalin, B. Baumlova, P. Baran, H. Oulyadi, A. Daich, J. Org. Chem. 2006, 71, 9114; b) T. Inokuma, Y. Hoashi, Y. Takemoto, J. Am. Chem. Soc. 2006, 128, 9413; c) G. Qiu Q. Ding, Y. Peng, J. Wu, Tetrahedron Lett. 2010, 51, 4391; d) C. G. Yan, X. K. Song, Q. F. Wang, J. Sun, U. Siemeling, C. Bruhn, Chem. Commun. 2008, 1440; e) J. Sun, E.-Y. Xia, L.
L. Zhang, C.-G. Yan, Eur. J. Org. Chem. 2009, 5247; f) J. Sun, L.-L. Zhang, E.-Y. Xia, C.-G. Yan, J. Org. Chem. 2009, 74, 3398; g) C. G. Yan, Q. F. Wang, X. K. Song, J. Sun, J. Org. Chem. 2009, 74, 710 .

[20] F. Shi, C. Li, M. Xia, K. Miao, Y. Zhao, S. Tu, W. Zheng, G. Zhang, N. Ma, Bioorg. Med. Chem. Lett. 2009, 19, 5565 .

[21] S. Tu, D. Zhou, L. Cao, C. Li, Q. Shao, J. Heterocyclic Chem. 2009, 46, 54.

[22] X.-H. Wang, X.-D. Cao, S.-J. Tu, X.-H. Zhang, W.-J. Hao, S. Yan, S.-S. Wu, Z.-G. Han, F. Shi, J. Heterocyclic Chem. 2009, 46, 886.

[23] B. Jiang, W.-J. Hao, X. Wang, F. Shi, S.-J. Tu, J. Comb. Chem. 2009, 11, 846.

[24] B. Jiang, X. Wang, F. Shi, S.-J. Tu, G. Li, Org. Biomol. Chem. 2011, 9, 4025.

[25] a) M. Heller, U. S. Schubert, J. Org. Chem. 2002, 67, 8269; b) C. Kaes, A. Katz, M. W. Hosseini, Chem. Rev. 2000, 100, 3553; c) I. Hussein, S. El, M. A. Z. Suhair, A. M. Mona, A. B. Farid, M. A. O. Abdulrahman, J. Med. Chem. 2000, 43, 2915; d) A. Gangjee, Y. Zeng, J. J. McGuire, R. L. Kisliuk, J. Med. Chem. 2002, 45,5173

[26] a) H. S. El-Kashef, A. A. Geies, E. D. A. M Kamal, A. A. Abdel-Hafez, J. Chem. Technol. Biotechnol. 1993, 57, 15; b) F. Haglid, Ark. Kemi 1967, 26, 489; c) J. Blagg, M. J. Fray, M. L. Lewis, J. P. Mathias, M. H. Stefaniak, A. Stobie, Chem. Abstr. 2003, 139, 261314 (Patent WO 2003076427).

[27] Z.-G. Han, S.-J. Tu, B. Jiang, S. Yan, X.-H. Zhang, S.-S. Wu, W.-J. Hao, X.-D. Cao, F. Shi, G. Zhang, N. Ma, Synthesis 2009, 1639.

[28] Z.-G. Han, C.-B. Miao, F. Shi, N. Ma, G. Zhang, S.-J. Tu, J. Comb. Chem. 2010, 12, 16

[29] S.-L. Wang, F.-Y. Wu, C. Cheng, G. Zhang, Y.-P. Liu, B. Jiang, F. Shi, S.-J. Tu, ACS Comb. Sci. 2011, 13, 135.

[30] B. Jiang, S.-J. Tu, P. Kaur, W. Wever, G. Li, J. Am. Chem. Soc. 2009, 131, 11660.

[31] B. Jiang, C. Li, F. Shi, S.-J. Tu, P. Kaur, W. Wever, G. Li, J. Org. Chem. 2010, 75, 2962.

[32] Q.-Y. Zhuang, X. Wang, Y. Gao, F. Shi, B. Jiang, S.-J. Tu, ACS Comb. Sci. 2011, 13, 84.

[33] A.S. Ivanov, Chem. Soc. Rev. 2008, 37, 789.

[34] P. Wei, X. Zhang, S. Tu, S. Yan, H. Ying, P. Ouyang, Bioorg. Med. Chem. Lett. 2009, 19, 828.

[35] J. Peng, W. Hao, X. Wang, S. Tu, N. Ma, G. Zhang, Chin. J. Chem. 2009, 27, 1707.

[36] J. Peng, R. Jia, Y. Xu, S. Tu, N. Ma, G. Zhang, Chin. J. Chem. 2009, 27, 2392.
[37] N. Ma, B. Jiang, G. Zhang, S.-J. Tu, W. Wever, G. Li, Green Chem. 2010, 12, 1357.

[38] F.-Y. Wu, Y. Li, H. Feng, Q. Wu, B. Jiang, F. Shi, S.-J. Tu, Synthesis 2011, 2459.

[39] a) S. Neelakantan, T. R. Seshadri, Curr. Sci. 1959, 28, 476; b) L. J. Haynes, J. R. Plimmer, Quarterly Rev. 1960, 14, 292.

[40] B. E. Roggo, F. Petersen, R. Delmendo, H. B. Jenny, H. H. Peter, J. Roesel, J. Antibiot. 1994, 47, 136.

[41] F. R. Foden, J. McCormick, D. M. O’Mant, J. Med. Chem. 1975, 18, 199.

[42] K. Luk, S. A. Readshaw, J. Chem. Soc., Perkin Trans. 1 1991, 1641.

[43] a) S. V. Ley, M. L. Trudell, D. J. Wadsworth, Tetrahedron 1991, 47, 8285; b) B. E. Vanwagenen, J. H. Cardellina, Tetrahedron 1986, 42, 1117; c) M. Matsumoto, Y. Kawamura, Y. Terui, H. Nakai, T. Yoshida, J. Shoji, J. Antibiot. 1990, 43, 739.

[44] A. Ibi, E. Yaniguchi, K. Maekawa, Agric. Biol. Chem. 1979, 43, 1641.

[45] a) A. Dal Pozzo, A. Dansi, E. Neneghini, Bull. Chim. Farm. 1974, 113, 280; b) A. Dal Pozzo, A. Dansi, E. Neneghini, Bull. Chim. Farm. 1974, 113, 324

[46] S.-J. Tu, X.-H. Zhang, Z.-G. Han, X.-D. Cao, S.-S. Wu, S. Yan, W.-J. Hao, G. Zhang, N. Ma, J. Comb. Chem. 2009, 11, 428.

[47] F. Shi, N. Ma, Y. Zhang, G. Zhang, B. Jiang, S Tu, Synth. Commun. 2010, 40, 235

[48] C. Cheng, B. Jiang, S.-J. Tu, G. Li, Green Chem. 2011, 13, 2107.

[49] S.-L. Wang, C. Cheng, F.-Y. Wu, B. Jiang, F. Shi, S.-J. Tu, T. Rajale, G. Li, Tetrahedron 2011, 67, 4485.

[50] S.-L. Wang, C. Cheng, F.-Y. Wu, J. Li, B. Jiang, S.-J. Tu, Chem. Lett. 2011, 40, 834

[51] B. Jiang, G. Zhang, N. Ma, F. Shi, S.-J. Tu, P. Kaur, G. Li, Org. Biomol. Chem. 2011, 9, 3834.

[52] a) R. Muller, H. Goesmann, H. Waldmann, Angew. Chem., Int. Ed. 1999, 38, 184; b) $\mathrm{H}$ Bohme, M. Haake, in 'Advances in Organic Chemistry', Ed. E. C. Taylor, John Wiley and Sons, New York, 1976, p 107.

[53] W.-J. Hao, B. Jiang, S.-J. Tu, X.-D. Cao, S.-S Wu, S. Yan, X.-H. Zhang, Z.-G. Han, F. Shi, Org. Biomol. Chem. 2009, 7, 1410.

[54] S.-L. Wang, W.-J. Hao, S.-J. Tu, X.-H. Zhang, X.-D. Cao, S. Yan, S.-S. Wu, Z.-G. Han, F. Shi, J. Heterocyclic Chem. 2009, 46, 664.

[55] F. Shi, J. Ding, S. Zhang, W.-J. Hao, C. Cheng, S. Tu, Bioorg. Med. Chem. Lett. 2011, 21,1554.

[56] B. Jiang, Y.-P. Liu, S.-J. Tu, Eur. J. Org. Chem. 2011, 3026. 